There is a wide-spread feeling that this form of government admits of improvement, and as the actual occupants of the posts in which an alteration is thought desirable stand deservedly very high in the estimation, not of the scientific world only, but in that of the community generally, the reform of which we are about to speak can fortunately now be discussed without personality, and without any fear of the acrimony to which, under less auspicious circumstances, such a discussion would ineviably lead.

The proposed alterations are of the very simplest kind, namely, that the tenure of office of the President should coincide with that of the rest of the Council, and that the Secretaries and Foreign Secretaries should be unpaid.

The inconveniences of the present arrangement, on which our space only admits of a few words, are, first, that however efficient, impartial, and undespotic the President and officers may be, their permanent tenure of their posts for a number of years in succession must tend to constitute them, in a Council undergoing yearly change, more or less an imperium in imperio. Indeed, their very efficiency and mastery of rule and precedent, in themselves most valuable attributes, aggravate, as well as generate, this tendency. The practical effect necessarily is, that the President and officers naturally and unavoidably get into the way of acting together, and of bringing before the Council matters for deliberation in somewhat of a cut and dried cundition. At the opening of the Session, the new members, it is well known, are naturally diffident of expressing views adverse to those thus prepared for their acceptance by such experienced hands; and it is a com. mon remark that it is only in his second year that a member serving on the Council for the first time usually declares his sentiments with independence and freedom. The choice, therefore, seems to lie between the experience which results from long service in the chair and secretariat, and the greater scope for deliberative activity, which limited service in those posts would afford.

In deciding between the two alternatives, the character of the Council must be considered. It contains a small selected section drawn from a large highly select body, the very crême de la crềne of the science and intellect of the kingdom, men who, one and all, are supposed to have gained their position by the most severe intellectual discipline, and who value that position as one of great responsibility and high honour. If chance, or favouritism, or money, or rank, had any appreciable influence on their election, the case would be very different. Some dry nursing might then be not amiss. But in the actual case, a Council composed of the flower of English intellect may safely be left to deliberate with unfettered republican freedom.

Another inconvenience attending the permanent, or rather unlimited, Presidentship, is one which may be indicated without in the slishtest degree applying it to the present distinguished occupant of the chair, namely, the extreme difficulty, without causing a scandal, of removing an inefficient or undesirable President.

A third inconvenience consists in the tendency towards an unduly Conservative policy, which a permanent President is liable to betray; and a fourth disadvantage is, that the particular department of Science to which the President is devoted is apt to be kept too continuously prominent. These tendencies are opposed to the vigor- ous progress and the wide expansion of scientific thought which it is the purpose of the Royal Society to foster.

We have but lightly touched upon the salient features of the question, which is one admitting of a vast variety of opinions, some of which, we trust, will be elicited by our remarks, for the appearance of which in these columns we feel that no apology is necessary.*

\section{THE GEOLOGY OF THE DIAMOND FIELDS OF SOUTH AFRICA}

I $N$ the September number of the Cape Monthly Magazine is an interesting article on the above subject, by Dr. John Shaw, Gold Medallist in Geology at Glasgow University, from which we have made the following extracts :-

"In February 1869, I published a paper in the Grahamstown fournal on the geological structure of the Vaal Regicn along the line where diamonds were founc. This was chielly intended as a reply to $\mathrm{Mr}$. Gregory's denial of the veritability of the discovery of diamonds $\mathrm{cn}$ various grounds, mainly geological and mineralogical, after a journey of exploration in the region.

"Since that time the finds of surface diamonds have increased, the stretch of couniry supposed to be diamondiferous has extended, and, at the present time, systematic digging and washing for diamonds are being carried on with an enthusiasm which success alone can have created, by upwards of $r, 000$ white men in different parts of the Vaal Region, but principally at Klipdrift, near Poreil.

"In July of this year I made considerable observations in the Vaal Valley, which show that the rocks are chiefly trappean, metamorphic, and conglomerate in character. 1 detected no pure granite formation, but syenite is, however, developed extensively, and seems to be the base of the whole system of rocks at Klipdrift. A very singular rock appears in the shape of isolated boulders on the summits of the Kopjes, and especially of the celebrated Old Kopje. This I take to be graphic granite (binary granite), or what Dana would call ' granilite,' consisting solely of quartz and large crystals of felspar.

"Above the syenite is a trap conglomerate in some places, in others are amygdaloids, and protruding through these again, basalt, assuming everywhere the hexagonal structure, and arising in some places into insulated and compacted columns.

"In some of the Kopjes there are remains of stratified rocks-clay schists, sandstone, chalk (or something very like it), which are evidently the last vestiges of a vast series of sedimentary strata, which formedy covered the whole present contour, but which have gradually given way to denudation and cataclysm.

"Such is the character of the present rock system at Klipdrift, and with a few additions (mainly supercumbent) of the whole rock series of the Vaal region.

"On the summits of the Kopjes, and as a matter of course, in the crevices between the basaltic boulders, is an alluvial gravel. In this are found the diamonds, and on the surface some have been found, indicators of the wealth beneath. The pebbles of sandstone, quartzite,

* The foregoing article, received from a valued contributor, is of so much importance that we have given it this prominence without committing ourselves to an approval of the precise course proposed; we rather invite discussion. - ED. 
crystalline sandstone, granite, clayslate, agate, tourmaline, iron pyrites, garnet, garnet spinel, \&c., which compose this alluvium, are all roundedly polished and waterworn, and are imbedded at Klipdrift in a brownish, fatty earth.

"The question ari es, Is this alluvium of recent or ancient formation? Did the majority of the febbles exist in the form of a conglomerate, aggregated from the alluvium of a former age? Or have the Kopjes at no very late period been the bed of the river?

"It is my opinion that the water-worn gravel has been under the influences of running water prior to the last great changes which formed the present landscape. The greater number of the water-worn pebbles and boulders are of the basalt of the Kopjes. Many of them are a crystallinesandstone, others are water-worn fragments of clayslate, sandstone, \&c., of the sedimentary rocks which exist in the Kopjes. The agates, tourmalines, and garnets are undoubtedly from some supercumbent conglomerate sandstone which has yielded to denudation and no longer exists at Klipdrift, and also to a considerable extent from the amygdaloidal trap everywhere prevalent. I have in my possession from the Vaal a single fragment of red sandstone containing garnets, but I have not succeeded in tracing this to its source.

"It will, therefore, be sufficiently apparent that there must have existed, at a remote geological period, a series of metamorphic and sedimentary rocks which lay above the present rock system of the region, and that, through successive disturbances and persistent denudation, these have been worn away, forming in great part the alluvial soil of the present surface. In some few spots remnants of this series still exist, as in the clay-slaty crystalline sandstone and conglomerate of Sitlacomies Valley, in the thin layers of claystone, sandstone, and micaceous sandstone of some of the Kopjes now worked for diamonds, and generally in the frogments of sedimentary rocks scattered over the surface along the whole Vaal Valley.

"I am decidedly inclined to think that the diamonds have not been washed down from some higher region. I hope to show in another article that the Free State possesses an independent diamondiferous centre, and that there no river has existed at any time, for there is no evidence of water-wearing, and the soil is not alluvial. Diamonds have been discovered two hours' distance from Potchefstroom, and all down the Vaal to its junction with the Orange River, and thence to ten hours' distance below Hope Town. This is a stretch of at least 500 miles. I believe the diamonds have come from some rock which may now have vanished, but which existed formerly throughout the whole region.

"In concluding at present, I have to make some observations on the position of the gravelly suil which is now being washed for diamonds. The old diggers are in favour of the summits of the Kopjes. They have tested this belief, or rather formed it, from their experience of the old Kopje. How can it be explained that the soil is alluvial and yet deposited far above the influences of the river? For two or three miles inland, which $I$ investigated, there is everywhere on the heights the same deposit.

"There are certain facts which enable me to point out the geological history of these Kopjes. The summits are all basalt. This has been protruded through the amygdaloidal and conglomerate traps. At a subsequent period, however, there must have been another elevation for the blocks and columns radiate from a centre, so that the crevices are wedge-shaped, or expanding outwards to the surface. This subsequent upheaval was evidently not simultaneous throughout the whole region, but successive, and therefore the bed of the stream was changed from place to place. The present bed of the Vaal cannot be an old one, and the whole surface of the country as far as the alluvial soil extends was, at different previous times, under the wearing and breaking influence of the river. Granting, then, a series of rocks such as have been described undergoing water-wearing by the ancient Vaal, which by intermittent and successive upheavals was compelled continually to change its course, and the presence of alluvial gravel on the summits of the Kopjes far and wide is easily explained.

"In the hollows no gravel is apparent, because a thick covering of sand, the accumulation of present denudation, lies over the gravel. Diggers do not care to undertake the labour of carrying off the surface sand at present. In time this will be done, and I am convinced there will be found more diamonds than on the Kopjes And when the day comes when the bed of the stream shall be searched by deflecting the water in canals through the many flats which abound in the Valley of the Vaal, a superior diamondiferous gravel will be worked. From all I saw and for the reason I have now advanced, the present diamond digging of South Africa is only trifling in comparison to what it should and will ultimately be."

\section{THE QUARTERLY WEATHER REPURT}

Quarterly Weather Report of the Meteorological Office, with Pressure and Temperature Tables for the Year I869. Part I. January-March, I 869.

$\mathrm{T} T$ is an arduous undertaking to establish and work a system which shall give us a perfectly full, trustworthy, and continuous account of the meteorology of even so small a part of the globe as the British Isles. The Meteorological Committee of the Royal Society are therefore deserving of credit in the systematic effort which they have made to establish the weather records of these isles upon a scientific foundation. Nor must we forget that our Government has been very liberal in this matter, and that a grant of $10,000 \%$. a year devoted to meteorology represents a very hand some contribution from that national purse which is, alas! so often shut when it ought to be open, and so ofter open when it ought to be shut.

Let us now consider how far the Committee have succeeded in advancing our knowledge of British Meteorology, and in what respect, if any, they have fal'en short o that which they might have been expected to accomplish. For this purpose let us divide the labours of the Committee into three heads, and consider separately their system of obtaining information, their system of discussing it, and, in the last place, their system of publication.

In the first place, and with respect to their observational system, it is hardly necessary to state that they have established seven observatories in which the various meteorological elements are registered continuously by means of photography, or that the Kew Observatory has 